\title{
Dietary antioxidant intake and cognitive performance in middle-aged adults
}

\author{
James M Peacock ${ }^{1}$, Aaron R Folsom ${ }^{1, *}$, David S Knopman ${ }^{2}$, Thomas H Mosley ${ }^{3}$, \\ David C Goff Jr ${ }^{4}$ and Moyses Szklo ${ }^{5}$ for the Atherosclerosis Risk in Communities (ARIC) \\ Study investigators \\ 'Division of Epidemiology, School of Public Health, University of Minnesota, Minneapolis, MN 55454-1015, \\ USA: ${ }^{2}$ Department of Neurology, Medical School, University of Minnesota, Minneapolis, MN, USA: ${ }^{3}$ Department \\ of Medicine (Geriatrics), University of Mississippi Medical Center, Jackson, MS, USA: ${ }^{4}$ Wake Forest University \\ School of Medicine, Winston-Salem, NC, USA: ${ }^{5}$ Department of Epidemiology, the Johns Hopkins Medical \\ Institutions, Baltimore, MD, USA
}

\begin{abstract}
Objective: To assess the cross-sectional association of dietary and supplemental antioxidant (carotenoids, vitamins C and E) intake with cognitive function in 12187 individuals, aged 48-67 years, participating in the Atherosclerosis Risk in Communities (ARIC) Study.

Methods: Dietary intake of antioxidant vitamins, as assessed by a food frequency questionnaire, and use of supplements were analysed in relation to the results of three cognitive tests, the delayed word recall test, the Wechsler adult intelligence scale, revised (WAIS-R) digit symbol subtest and the word fluency test.

Results: After adjustment for covariates previously found to be associated with cognition in this sample, we found no consistent associations between dietary antioxidant vitamin intake or supplement use and any of the cognitive tests. Conclusions: This study suggests little, if any, association between antioxidant vitamin intake and better cognitive function in middle-aged adults.
\end{abstract}

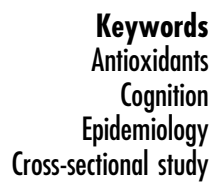

Keywords

Cognition

Epidemiology

Cross-sectional study
Cognitive decline and dementia associated with Alzheimer's disease (AD) are major contributors to morbidity in the elderly ${ }^{1,2}$. The accumulation of free radicals, leading to oxidative damage in brain tissue, has been implicated as a major contributor to this disorder. Oxidative stress has been shown to cause cell damage and neuronal death in animal models and cell culture. Additional support for the possible pathological role of oxidative stress comes from clinical and epidemiological investigations ${ }^{3}$. For example, significant deficits of the antioxidant vitamin $\mathrm{E}$ have been noted in the cerebrospinal fluid of AD patients ${ }^{4}$. Similarly, reduced plasma concentrations of vitamins $\mathrm{A}$ and $\mathrm{E}$, and $\beta$-carotene have been reported in $\mathrm{AD}$ patients ${ }^{5}$. A crosssectional study of 5182 community-dwelling older adults in the Netherlands found that lower levels of dietary intake of $\beta$-carotene were associated with poor cognition ${ }^{6}$. Another study in Switzerland showed significant crosssectional and longitudinal relationships between increased levels of $\beta$-carotene and vitamin $\mathrm{C}$ and better cognitive performance in the old and very old ${ }^{7}$. A recent report using cross-sectional data from the third National Health and Nutrition Examination Survey indicated a significant association between poor memory and lower serum vitamin E levels, but no association of memory with any other serum antioxidant measured ${ }^{8}$. A small cohort study in Australia showed a significant protective effect of vitamin $\mathrm{C}$ intake with one measure of cognitive impairment ${ }^{9}$, but another study in the USA showed no association between use of antioxidant supplements and cognitive function ${ }^{10}$.

Recent evidence suggests that antioxidants from diet or vitamin supplements can reduce the risk of cognitive decline associated with ageing. Clinical trials indicate that long-term treatment with vitamin $\mathrm{E}$ can slow the progression of $\mathrm{AD}^{11}$, and that increases in vitamin $\mathrm{C}$ and vitamin $\mathrm{E}$ levels are associated with improved cognitive performance in older populations ${ }^{12}$.

We previously reported associations of several physiological and behavioural characteristics with cognitive performance in the ARIC cohort $^{13}$. In this analysis we tested the hypothesis that higher levels of antioxidant vitamin intake are associated with better cognitive function in this biracial, middle-aged sample of men and women.

\section{Research design and methods}

\section{Study population}

The ARIC Study ${ }^{14}$ is a multicentre prospective cohort study investigating the aetiology of atherosclerotic disease in a middle-aged, biracial population. One aspect of the study includes examination and follow-up of population-based 
cohorts of 45-64 year olds from Forsyth County, NC; Jackson, MS (African-Americans only); the northwest suburbs of Minneapolis, MN; and Washington County, MD. During 1987 to 1989, a baseline home interview assessed participants' health behaviours, sociodemographic characteristics and disease histories. A clinical examination included measurements of cardiovascular conditions, various risk factors, a dietary questionnaire and a B-mode ultrasound examination of selected arterial sites. Approximately $46 \%$ of eligibles in Jackson and $65 \%$ in the other three communities completed a home interview and clinical examination, yielding a total of 15792 participants. Ninety-three per cent of participants still alive completed a second visit in 1990-1992, and 86\% completed a third visit in 1993-1995. Cognitive function was assessed at the second ARIC clinical examination.

\section{Cognitive function tests}

Cognitive function was measured by three neuropsychological tests: the delayed word recall test ${ }^{15}$, the WAIS-R digit symbol subtest ${ }^{16}$ and the controlled oral word association (or word fluency) test ${ }^{18}$ of the Multilingual Aphasia Examination ${ }^{18}$. The tests were administered by trained interviewers in a standardized order during one session in a quiet room. Interviewer performance was monitored by tape recording and reviewing a sample of the testing sessions, and by confirming that there were no systematic differences in mean scores obtained by the different interviewers who gave the tests.

The delayed word recall test is a test of verbal learning and recent memory that requires the participant to recall 10 common nouns following a $5 \mathrm{~min}$ interval during which another psychometric test is given. To standardize elaborative processing of the words to be recalled, individuals are asked to compose sentences incorporating the nouns as presented. Test scores ranged from zero to 10 words recalled. The delayed word recall test has been found to have a 6-month test-retest reliability of 0.75 in 26 normal elderly individuals ${ }^{15}$.

The WAIS-R digit symbol subtest is a paper-and-pencil task requiring timed translation of numbers (1 through 9) to symbols using a key. The test measures psychomotor performance and is relatively unaffected by intellectual ability, memory or learning ${ }^{17}$. It is a sensitive and reliable indicator of brain damage ${ }^{19,20}$; however, since it measures many different components of performance it is not useful in localizing a lesion ${ }^{17}$. The digit symbol subtest is scored as the number of numbers translated to symbols correctly within $90 \mathrm{~s}$, up to a possible maximum of 93 . Test-retest reliability over $2-5$ weeks has been reported to be 0.82 in 45-54 year olds ${ }^{16}$.

The word fluency test requires the participant to generate as many words as possible beginning with the letter F, A and S (as many as possible in $60 \mathrm{~s}$, for each letter). The test is particularly sensitive to damage to the frontal lobes of the brain, especially the left frontal lobe ${ }^{17,21}$. The score is the total number of words generated. Reliability based on an alternate test has been reported to be $0.82^{22}$.

\section{Antioxidant intake}

Usual intake of dietary and supplemental carotenoids and vitamins $\mathrm{C}$ and $\mathrm{E}$ was determined by two questionnaires. First, dietary information over the last year was collected at the first visit using a modified version of Willett's 61-item food frequency questionnaire ${ }^{23}$. Reliability coefficients over a 3-year interval for these three antioxidant vitamins ranged from 0.29 to 0.63 for the four race-sex groups ${ }^{24}$, which is slightly lower than those reported over 1 year in a sample of white women $(r=0.52-0.62)^{23}$. Reliability was higher in whites than African-Americans and in men than women and increased with increasing age and education ${ }^{24}$. The questionnaire was administered by trained interviewers. Dietary antioxidant vitamin intake was computed by multiplying the antioxidant vitamin content of each food item by the frequency of its daily consumption and summing over all items. Individuals were also asked about their use of single- and multivitamin supplements as part of a medication survey. ARIC participants were asked to bring to both ARIC visits all medications and supplements taken in the previous 2 weeks. Use of antioxidant vitamins was recorded from bottles brought in by the participants. Dose and duration of use were not asked.

\section{Other measurements}

Most other measurements used in this analysis were obtained during the second ARIC visit, except for plasma fibrinogen and dietary antioxidant intake (only baseline examination measures were available)

Blood pressure was measured three times using a random-zero sphygmomanometer. The mean of the last two measurements was used for analysis. Hypertension was defined as systolic blood pressure $\geqslant 140 \mathrm{mmHg}$ or diastolic blood pressure $\geqslant 90 \mathrm{mmHg}$ or in a person currently taking antihypertensive medication. Pulmonary function was assessed using a calibrated spirometer according to American Thoracic Society standards. Vital capacity and forced expiratory volume $\left(\mathrm{FEV}_{1}\right)$ were derived.

Carotid artery intima-media thickness (a marker for atherosclerosis) was determined by high resolution B-mode ultrasound as previously described in detail ${ }^{25,26}$. Intima-media thickness was measured at three sites (bilaterally): the distal $1.0 \mathrm{~cm}$ straight portion of the common carotid artery, the carotid bifurcation and the proximal $1.0 \mathrm{~cm}$ of the internal carotid artery. Some degree of missing data occurred, for which values were imputed ${ }^{27}$ from wall thickness measurements at the visualized sites. For analysis, we took the overall unweighted average of the mean intima-media wall thickness (measured or imputed) of the six carotid arterial segments. 
Participants were asked to fast for 12 hours prior to the clinic examination. Blood was drawn from the antecubital vein of seated participants using minimal trauma. Specimens were collected into vacuum tubes and stored at $-70^{\circ} \mathrm{C}$ until analysis within a few weeks. Plasma fibrinogen was measured by the thrombin time titration method ${ }^{28}$ with reagents and calibration materials (Fibriquik) obtained from General Diagnostics (Organon-Technika Co., Morris Plains, NJ).

Marital status, education level, employment status and smoking were assessed by standardized interviews. Education level was categorized using cut-off points of ninth grade, high school graduation, completion of college or vocational school, and completion of graduate or professional school. Thirteen depression items from the Maastricht Questionnaire ${ }^{29}$ were used to define a depression symptoms score (range 0 to 26 , low to high). We recorded use of antipsychotic drugs, benzodiazepines, antidepressants and analgesic narcotics from bottles brought in by the participants.

\section{Data analysis}

We hypothesized that, compared to higher intake of carotenoids and vitamins $\mathrm{C}$ and $\mathrm{E}$, lower intake of these antioxidant vitamins would be associated with lower cognitive function test performance at visit 2. Each of the three cognitive function test scores was dichotomized at approximately the lowest performing 10\%. The cut-off points were: word recall test $(0-4,5-10)$, digit symbol test $(0-26,27-93)$ and word fluency test $(0-18,19-99)$. Although the lowest decile may not represent severe impairment, for ease of presentation we refer to those participants as having 'poor cognition'. Of 15792 ARIC participants, we excluded from the analysis 1664 who did not come to visit 2 and perform cognitive tests, 295 who had extreme caloric intake (the upper and lower one percentiles of total calories ingested), 146 who reported a history of stroke, 105 who were currently using antipsychotic drugs, 679 who were currently using benzodiazepines, 409 who were currently using antidepressants and 307 more who were currently using analgesic narcotics. We excluded those using these medications based upon an a priori expectation of association with cognitive function. This left a maximum sample size for analysis of 12187 .

The relationship of a wide variety of risk factors to cognitive function in this population has previously been reported $^{13}$. The most important correlates of cognitive function were depressive symptoms, smoking, drinking, $\mathrm{FEV}_{1}$, physical activity, diabetes, fibrinogen and carotid intima-media wall thickness. To identify potential confounding variables, age-, race-, sex-, ARIC field centre- and education-adjusted means and percentages for those variables correlated with cognitive function test scores ${ }^{13}$ were calculated using analysis of covariance, for four levels of intake for each of the three antioxidant vitamins. A global $F$-test for equality across all quartiles of antioxidant intake was performed. Participants not taking any antioxidant vitamin supplements at visit 1 were categorized into quartiles of dietary intake for each antioxidant vitamin. Then, on the assumption that supplementation resulted in high antioxidant intake, users of single- and multivitamin supplements at visit 1 were assigned to the highest (fourth) level of vitamin intake.

We used logistic regression models to calculate the multivariate adjusted odds ratio of poor cognition in relation to the four levels of each antioxidant vitamin modelled separately. A chi-square test for trend in odds ratios across the four levels of intake was calculated, assigning each level an integer value identical to the intake group, i.e. 1, 2, 3, 4. We also calculated the multivariateadjusted odds ratio of poor cognition in relation to use of antioxidant supplements, either as multi- and single vitamin or single vitamin supplements only. In model 1 we adjusted for age, sex, ARIC field centre, race (AfricanAmerican, other), education ( $<$ high school, high school, college or vocational school, graduate school), employment status (retired, other), marital status (married, unmarried), depressive symptoms and total caloric intake because they were related to both cognitive function and antioxidant intake. In model 2 we added other factors that appeared to be confounding variables: fibrinogen, cigarette years of smoking, sport activity index, waisthip ratio, carotid intima-media thickness, $\mathrm{FEV}_{1}$, hypertension and hormone replacement therapy (women only). Model 2 and model 1 yielded similar results, therefore we have chosen to report results from model 2 only.

\section{Results}

\section{Descriptive data}

The analysis included 12187 individuals aged 48-67 years who participated in cognitive function tests at visit 2 . The number of individuals with low cognitive scores in this analysis was 950 for the word recall test, 1349 for the digit symbol test and 1369 for the word fluency test. The cognition scores were correlated as follows: word recall/ digit symbol, 0.38; word recall/word fluency, 0.29; digit symbol/word fluency, 0.51 .

Table 1 shows correlates of poor cognitive function according to four levels of dietary vitamin $\mathrm{E}$ intake. Compared to the lowest intake group (level I), those in the highest intake group (level IV) were less likely to be retired, and more likely to be male, African-American and to have completed college, vocational school or graduate school. Level IV users, on average, were older, had a higher sport activity index score, less cigarette smoking exposure, and higher total caloric intake. Generally, these factors were similarly related to dietary carotenoid and vitamin C intake (data not shown). 
Table 1 Sex-, age-, race-, field centre- and education-adjusted percentages and means of possible risk factors according to levels of dietary vitamin $\mathrm{E}$ intake

\begin{tabular}{|c|c|c|c|c|c|}
\hline & \multicolumn{4}{|c|}{ Dietary vitamin E intake* } & \multirow[b]{2}{*}{$P$ value† } \\
\hline & $\begin{array}{c}\mathrm{I} \\
(n=2249)\end{array}$ & $\begin{array}{c}\text { II } \\
(n=2259)\end{array}$ & $\begin{array}{c}\text { III } \\
(n=2252)\end{array}$ & $\begin{array}{c}\text { IV } \\
(n=2258)\end{array}$ & \\
\hline \multicolumn{6}{|l|}{ Percentages } \\
\hline Male & 46.5 & 45.9 & 49.3 & 52.0 & 0.0001 \\
\hline African-American & 26.9 & 27.5 & 27.8 & 29.6 & 0.0001 \\
\hline$<$ High school & 24.5 & 22.6 & 21.1 & 21.3 & 0.01 \\
\hline Retired & 24.8 & 21.7 & 22.8 & 21.7 & 0.01 \\
\hline Married & 78.1 & 80.1 & 80.4 & 80.9 & 0.08 \\
\hline Hypertensive & 37.0 & 35.8 & 35.9 & 33.7 & 0.11 \\
\hline Hormone replacement therapy (women only) & 20.9 & 21.6 & 22.5 & 23.5 & 0.49 \\
\hline \multicolumn{6}{|l|}{ Means } \\
\hline Age (years) & 56.4 & 56.9 & 56.8 & 57.3 & 0.0001 \\
\hline Waist-hip ratio & 0.931 & 0.929 & 0.931 & 0.929 & 0.55 \\
\hline Sport activity index (range $0-5$ ) & 2.35 & 2.41 & 2.45 & 2.50 & 0.0001 \\
\hline Fibrinogen $\left(\mathrm{mg} \mathrm{dl}^{-1}\right)$ & 302 & 303 & 301 & 301 & 0.45 \\
\hline Smoking (cigarette years) & 344 & 333 & 300 & 306 & 0.0005 \\
\hline Carotid intima-media thickness $(\mathrm{mm})$ & 0.760 & 0.750 & 0.752 & 0.750 & 0.22 \\
\hline $\mathrm{FEV}_{1}$ (litres) & 0.906 & 0.911 & 0.916 & 0.916 & 0.26 \\
\hline Depression score (range 0-26) & 6.85 & 6.78 & 6.80 & 6.97 & 0.53 \\
\hline Total calories $\left(\mathrm{kcal}^{\mathrm{day}}{ }^{-1}\right)$ & 1093 & 1422 & 1723 & 2172 & 0.0001 \\
\hline
\end{tabular}

* Intake level $\mathrm{I}=<3.03$, level $\mathrm{II}=3.03-4.15$, level $\mathrm{III}=4.16-5.75$ and level $\mathrm{IV}=>5.75 \mathrm{mg} \mathrm{day}^{-1}$.

$\dagger F$-test for equality across all quartiles of dietary vitamin $E$ intake.

In addition, we assessed the association of these correlates of poor cognitive function with use of antioxidant vitamin supplements (data not shown). Those taking vitamin E supplements or multivitamins containing vitamin $\mathrm{E}$ were more likely to be married, to be receiving hormone replacement therapy (women only), less likely to be hypertensive, had a smaller waist-hip ratio, lower plasma fibrinogen levels, smaller carotid intima-media thickness, and higher forced expiratory volume. Once again, these relations were similar for

Table 2 Adjusted ${ }^{*}$ odds ratios (OR) and 95\% confidence intervals of poorer cognitive function according to current use of antioxidant vitamin supplements

\begin{tabular}{|c|c|c|c|c|c|}
\hline & \multicolumn{4}{|c|}{ Antioxidant vitamin intake } & \multirow[b]{2}{*}{$P$ trend $\dagger$} \\
\hline & I & II & III & IV & \\
\hline $\begin{array}{l}\text { Carotenoids } \\
\text { Intake (IU day }{ }^{-1} \text { ) }\end{array}$ & $\begin{array}{c}n=2254 \\
<3290\end{array}$ & $\begin{array}{l}n=2255 \\
n=213\end{array}$ & $n=2255$ & $n=2254$ & \\
\hline $\begin{array}{l}\text { Intake (IU day ) } \\
\text { Word recall (OR) }\end{array}$ & $\begin{array}{l}<3290 \\
1.00\end{array}$ & $\begin{array}{c}3290-5313 \\
1.15\end{array}$ & $\begin{array}{c}5314-1021 / \\
1.22\end{array}$ & $\begin{array}{l}>1021 / \\
1.08\end{array}$ & 0.51 \\
\hline $95 \% \mathrm{Cl}$ & Reference & $0.90-1.47$ & $0.95-1.56$ & $0.83-1.41$ & \\
\hline Digit symbol (OR) & 1.00 & 0.75 & 0.83 & 0.84 & 0.37 \\
\hline $95 \% \mathrm{Cl}$ & Reference & $0.56-1.00$ & $0.63-1.11$ & $0.84-1.12$ & \\
\hline Word fluency (OR) & 1.00 & 0.93 & 0.85 & 0.99 & 0.68 \\
\hline $95 \% \mathrm{Cl}$ & Reference & $0.75-1.14$ & $0.68-1.05$ & $0.78-1.24$ & \\
\hline Vitamin C & $n=2254$ & $n=2256$ & $n=2254$ & $n=2254$ & \\
\hline Intake $\left(\mathrm{mg} \mathrm{day}^{-1}\right)$ & $<68.5$ & $68.5-108.0$ & $108.1-161.1$ & $>161.1$ & \\
\hline Word recall (OR) & 1.00 & 1.24 & 1.10 & 1.26 & 0.19 \\
\hline $95 \% \mathrm{Cl}$ & Reference & $0.97-1.59$ & $0.85-1.42$ & $0.96-1.65$ & \\
\hline Digit symbol (OR) & 1.00 & 1.06 & 0.96 & 0.96 & 0.68 \\
\hline $95 \% \mathrm{Cl}$ & Reference & $0.80-1.41$ & $0.72-1.28$ & $0.71-1.31$ & \\
\hline Word fluency (OR) & 1.00 & 1.00 & 1.04 & 1.03 & 0.76 \\
\hline $95 \% \mathrm{Cl}$ & Reference & $0.80-1.24$ & $0.83-1.30$ & $0.81-1.30$ & \\
\hline Vitamin $E$ & $n=2249$ & $n=2259$ & $n=2252$ & $n=2258$ & \\
\hline Intake $\left(\mathrm{mg} \mathrm{day}^{-1}\right)$ & $<3.03$ & $3.03-4.15$ & $4.16-5.75$ & $>5.75$ & \\
\hline Word recall (OR) & 1.00 & 0.94 & 0.95 & 0.98 & 0.89 \\
\hline $95 \% \mathrm{Cl}$ & Reference & $0.43-1.22$ & $0.72-1.24$ & $0.71-1.34$ & \\
\hline Digit symbol (OR) & 1.00 & 1.13 & 0.88 & 0.87 & 0.24 \\
\hline $95 \% \mathrm{Cl}$ & Reference & $0.84-1.52$ & $0.64-1.21$ & $0.60-1.26$ & \\
\hline Word fluency (OR) & 1.00 & 1.00 & 1.02 & 1.06 & 0.66 \\
\hline $95 \% \mathrm{Cl}$ & Reference & $0.80-1.25$ & $0.80-1.31$ & $0.80-1.42$ & \\
\hline
\end{tabular}

* Models adjusted for age, sex, field centre, race, education, employment status, marital status, depression score, total caloric intake fibrinogen, smoking status, sport activity index, waist-hip ratio, carotid intima-media thickness, FEV ${ }_{1}$, hypertension and hormone replacement therapy (women only). † Chi-square test for linear trend 
vitamin A and C supplement use.

Table 2 shows the odds ratio (OR) for poor cognitive function for the four different levels of dietary antioxidant vitamin intake, after excluding users of dietary antioxidant vitamin supplements. An OR of $<1.00$ represents a positive association between intake of antioxidants and better cognitive performance. After adjustment for multiple confounding variables, we found no statistically significant association between dietary intake of any of the three antioxidant vitamins, categorized in four levels, and cognitive performance.

We also tested the association of antioxidant vitamin supplementation at visit 2 , either in the form of single or multivitamin supplements, with cognitive function test scores. The first column in Table 3 shows the OR estimate of poorer cognitive function associated with use of each type of supplement exclusively versus using no supplement at all; individuals using multiple supplements were deleted from the analysis. The third column shows the OR estimate for a broader definition of supplement use, and includes individuals taking any of these vitamin supplements, either as a single supplement or as part of a multivitamin supplement. We again found no significant association of use of any antioxidant vitamin supplement with cognitive performance as measured by any of the three tests.

We also performed all analyses using education-specific cut-off scores for all three cognitive tests. Dichotomizing at the lowest $10 \%$, the cut-off points for those not completing high school were: word recall test (0-4, 5-10), digit symbol test $(0-15,16-80)$ and word fluency test $(0-10$, 11-64). The cut-off points for high school graduates were: word recall test $(0-5,6-10)$, digit symbol test $(0-33$, 34-93) and word fluency test (0-21, 22-99). Other analyses included the association of antioxidant vitamin supplement use in those in the lowest quartile of dietary antioxidant vitamin consumption, and the association of absolute dietary antioxidant vitamin intake (ignoring total calories consumed) in those not using antioxidant vitamin supplements with cognitive test scores. We also looked at total intake of antioxidant vitamins by including all individuals taking antioxidant vitamin supplements with those in the highest category (quartile IV) of dietary intake (Table 2). Another analysis looked at the effect of supplement use in those in the 25th percentile of antioxidant vitamin consumption. In addition, we performed a sensitivity analysis, redefining the cut-off points as the lowest performing $5 \%$ and $15 \%$ on each of

Table 3 Adjusted ${ }^{*}$ odds ratios (OR) and 95\% confidence intervals of poorer cognitive function according to current use of antioxidant vitamin supplements†

\begin{tabular}{|c|c|c|c|c|}
\hline & $\begin{array}{l}\text { Single supplement } \\
\text { use only }\end{array}$ & $P$ value $\neq$ & $\begin{array}{l}\text { Single or multiple } \\
\text { supplement use }\end{array}$ & $P$ value \\
\hline Multivitamin supplements & $n=1692$ & & $n=3169$ & \\
\hline Word recall (OR) & 0.92 & 0.49 & 1.00 & 0.99 \\
\hline $95 \% \mathrm{Cl}$ & $0.72-1.16$ & & $0.84-1.20$ & \\
\hline Digit symbol (OR) & 0.80 & 0.10 & 0.82 & 0.09 \\
\hline $95 \% \mathrm{Cl}$ & $0.61-1.05$ & & $0.66-1.03$ & \\
\hline $\begin{array}{l}\text { Word fluency (OR) } \\
95 \% \mathrm{Cl}\end{array}$ & $\begin{array}{c}1.02 \\
0.83-1.26\end{array}$ & 0.83 & $\begin{array}{c}0.93 \\
0.79-1.10\end{array}$ & 0.40 \\
\hline Vitamin $A$ & $n=31$ & & $n=115$ & \\
\hline $\begin{array}{l}\text { Word recall (OR) } \\
95 \% \mathrm{Cl}\end{array}$ & $\begin{array}{c}1.05 \\
0.23-4.75\end{array}$ & 0.95 & $\begin{array}{c}1.08 \\
0.53-2.18\end{array}$ & 0.84 \\
\hline $\begin{array}{l}\text { Digit symbol (OR) } \\
95 \% \mathrm{Cl}\end{array}$ & $\begin{array}{c}1.95 \\
0.37-10.4\end{array}$ & 0.44 & $\begin{array}{c}0.95 \\
0.45-1.98\end{array}$ & 0.88 \\
\hline $\begin{array}{l}\text { Word fluency (OR) } \\
95 \% \mathrm{Cl}\end{array}$ & $\begin{array}{c}1.59 \\
0.48-5.32\end{array}$ & 0.45 & $\begin{array}{c}1.05 \\
0.56-1.96\end{array}$ & 0.88 \\
\hline Vitamin $C$ & $n=285$ & & $n=743$ & \\
\hline $\begin{array}{l}\text { Word recall (OR) } \\
\quad 95 \% \mathrm{Cl}\end{array}$ & $\begin{array}{c}1.21 \\
0.75-1.96\end{array}$ & 0.44 & $\begin{array}{c}1.11 \\
0.79-1.54\end{array}$ & 0.55 \\
\hline $\begin{array}{l}\text { Digit symbol (OR) } \\
95 \% \mathrm{Cl}\end{array}$ & $\begin{array}{c}0.92 \\
0.48-1.75\end{array}$ & 0.79 & $\begin{array}{c}0.81 \\
0.51-1.31\end{array}$ & 0.39 \\
\hline $\begin{array}{l}\text { Word fluency (OR) } \\
\qquad 95 \% \mathrm{Cl}\end{array}$ & $\begin{array}{c}1.03 \\
0.65-1.65\end{array}$ & 0.89 & $\begin{array}{c}0.84 \\
0.59-1.17\end{array}$ & 0.30 \\
\hline Vitamin $E$ & $n=159$ & & $n=386$ & \\
\hline $\begin{array}{l}\text { Word recall (OR) } \\
95 \% \mathrm{Cl}\end{array}$ & $\begin{array}{c}1.20 \\
0.62-2.32\end{array}$ & 0.60 & $\begin{array}{c}1.13 \\
0.72-1.78\end{array}$ & 0.60 \\
\hline $\begin{array}{l}\text { Digit symbol (OR) } \\
95 \% \mathrm{Cl}\end{array}$ & $\begin{array}{c}1.19 \\
0.57-2.48\end{array}$ & 0.65 & $\begin{array}{c}0.90 \\
0.52-1.57\end{array}$ & 0.71 \\
\hline $\begin{array}{l}\text { Word fluency (OR) } \\
99 \% \mathrm{Cl}\end{array}$ & $\begin{array}{c}0.90 \\
0.49-1.67\end{array}$ & 0.75 & $\begin{array}{c}1.00 \\
0.67-1.50\end{array}$ & 0.99 \\
\hline
\end{tabular}

${ }^{*}$ Models adjusted for age, sex, field centre, race, education, employment status, marital status, depression score, total caloric intake, fibrinogen, smoking status, sport activity index, waist-hip ratio, carotid intima-media thickness, FEV ${ }_{1}$, hypertension and hormone replacement therapy (women only).

$\dagger$ Reference group for all comparisons is non-users of any supplement, $n=9018$. $\ddagger$ Wald chi-square statistic. 
the cognitive tests. These analyses did not change the conclusion of no association between antioxidant vitamins and cognitive test performance (data not shown).

\section{Discussion}

The primary goal of this study was to examine the relationship of antioxidant vitamin intake with cognitive performance in a middle-aged population-based sample of men and women. Even though dementia is most common in old age, slight cognitive deficits at middle age may provide an early indication of future cognitive decline. If this is true, early detection of these deficits may enable us to intervene at an earlier stage and alter or delay the progression of these disorders. A previous report ${ }^{13}$ described correlations of cognitive function in this ARIC cohort, and those that were significantly related to carotenoids and vitamins $\mathrm{C}$ or $\mathrm{E}$ were considered in order to reduce possible confounding in this cross-sectional analysis.

We found no significant association between level of total antioxidant vitamin intake and any of the cognitive function tests, in spite of multiple comparisons being tested. Because of no consistent association between use of any of the antioxidant vitamins and cognitive function, this study suggests that in the general population antioxidant vitamin intake is, at best, weakly associated with cognitive function.

The strengths of our study include its large, biracial population-based cohort and careful assessments. Additionally, the tests we have used as our dependent measures are more sensitive than the mental status examinations used in many studies. Limitations of our study may include possible selection bias; that is, those with poorer cognition may be less likely to obtain the recommended daily allowance of many nutrients. However, few of the participants had severe cognitive impairment. In addition, our study population is younger and the prevalence of cognitive dysfunction is lower than in many other studies. Despite the large size of this cohort, we may not have the power to detect very small effects. The inherent unreliability of dietary questionnaires would tend to impair our ability to detect associations. Also, current dietary habits may not necessarily represent historical dietary intake of antioxidant vitamins. It should also be noted that we only had dietary intake information from visit 1, 3 years prior to the administration of the cognition examinations. In addition, we had no information on dose or duration of use of the antioxidant vitamin supplements.

Our study does not support recent reports of significant associations between antioxidant intake and cognitive function. Cross-sectional studies indicating a significant deficit of dietary antioxidants in the plasma and spinal fluid were done in AD patients ${ }^{4,5}$. Cross-sectional dietary analyses $^{6,8}$ and prospective studies of plasma antioxidants ${ }^{7}$ were performed in the old or very old. A small cohort study of retirement community residents in Australia found an association between vitamin $C$ intake and only one measure of cognitive function ${ }^{9}$. Another cohort study of elderly participants living in rural Pennsylvania showed no association between vitamin C intake (dietary or supplements) and cognitive function ${ }^{10}$.

Antioxidant therapies are often mentioned as possible means to reduce the risk of $\mathrm{AD}$ and to slow progression of the disease $\mathrm{e}^{30,31}$, and a recent clinical trial has shown that long-term treatment with vitamin $\mathrm{E}$ can slow the progression of $\mathrm{AD}^{11}$. Another trial has shown that increases in vitamin $\mathrm{C}$ and vitamin $\mathrm{E}$ levels are associated with improved cognitive performance in older populations $^{12}$. However, there remains no evidence that antioxidant supplementation is related to better cognition in younger adults ${ }^{32}$.

Even though we were unable to find a consistent association between antioxidant intake and cognition in our middle-aged population, there remains some evidence of a significant beneficial effect of vitamin $\mathrm{E}$ in those with $\mathrm{AD}^{11}$. Although the causes of $\mathrm{AD}$ and age-related cognitive decline are as yet unknown, oxidative stress and excess lipid peroxidation may be related to both. If so, effective antioxidant therapies to halt or slow cognitive decline attributed to normal ageing would be of great importance. A modest, or even short-term, effect of antioxidants on cognition could have a substantial impact upon quality of life, particularly for older adults. The inconsistent results in the literature may be due to different measures of antioxidants or cognitive performance, as well as the diverse population samples being studied. More precise information on dietary intake and supplement dose and duration will make population studies in this area more useful.

\section{Acknowledgements}

The ARIC Study was funded by contracts N01-HC-55015, N01-HC-55016, N01-HC-55018, N01-HC-55019, N01-HC55020, N01-HC-55021 and N01-HC-55022 from the US National Heart, Lung, and Blood Institute.

The authors thank the following ARIC personnel: Phillis Johnson, Marilyn Knowles and Catherine Paton from the University of North Carolina, Chapel Hill, NC; Jennette Bensen, Kay Burke, Wilhelmenia Cheeks and Revitha Cook from the University of North Carolina, Forsyth County, NC; Betty Warren, Dorothy Washington, Mattye Watson and Nancy Wilson from the University of Mississippi Medical Center, Jackson, MS; Caryl DeYoung, Mary Doberstein, Chris Dwight and Greg Feitl from the University of Minnesota, Minneapolis, MN; Patricia Slagle, Serena Bell, Pam Bowers and Joyce Chabot from the Johns Hopkins University, Baltimore, MD; Valerie Stinson, Pam Pfile, Hogan Pham and Teri Trevino from the University of 
Texas Medical School, Houston, TX; Wanda Alexander, Doris Harper, Charles Rhodes and Selma Soyal from the Methodist Hospital, Atherosclerosis Clinical Laboratory, Houston, TX; Suzanne Pillsbury, Tiffany Robertson, Anne Safrit and Melanie Wilder from the Bowman-Gray School of Medicine, Ultrasound Reading Center, Winston-Salem, NC; and Thomas Goodwin, Steve Hutton, Jean Johnson and Doris Jones from the ARIC Coordinating Center, University of North Carolina, Chapel Hill, NC.

\section{References}

1 Evans DA, Funkenstein HH, Albert MS, et al. Prevalence of Alzheimer's disease in a community population of older persons: higher than previously reported. JAMA 1989; 262 : 2551-6.

2 Bachman DL, Wolf PA, Linn R, et al. Prevalence of dementia and probable senile dementia of the Alzheimer type in the Framingham Study. Neurology 1992; 42: 115-19.

3 Packer L, Miramatsu M, Toshikawa T. Free Radicals in Brain Physiology and Disorders. San Diego: Academic Press, 1996.

4 Tohgi H, Abe T, Nakanishi M, Hamato F, Sasaki K, Takahashi $\mathrm{S}$. Concentrations of alpha-tocopherol and its quinone derivative in cerebrospinal fluid from patients with vascular dementia of the Binswanger type and Alzheimer type dementia. Neurosci. Lett. 1994; 174: 73-6.

5 Zaman Z, Roche S, Fielden P, Frost PG, Niriella DC, Cayley $\mathrm{ACD}$. Plasma concentrations of vitamins $\mathrm{A}$ and $\mathrm{E}$ and carotenoids in Alzheimer's disease. Age Ageing 1992; 21: 91-4.

6 Jama JW, Launer LJ, Wittemen JCM, et al. Dietary antioxidants and cognitive function in a population-based sample of older persons. Am. J. Epidemiol. 1996; 144(3): 275-80.

7 Perrig WJ, Perrig P, Stähelin HB. The relation between antioxidants and memory performance in the old and very old. J. Am. Geriatr. Soc. 1997; 45: 718-24.

8 Perkins AJ, Hendrie HC, Callahan CM, et al. Association of antioxidants with memory in a multiethnic sample using the third National Health and Nutrition Examination Survey. Am. J. Epidemiol. 1999; 150(1): 37-44.

9 Paleologos M, Cumming RG, Lazarus R. Cohort study of vitamin $\mathrm{C}$ intake and cognitive impairment. Am. J. Epidemiol. 1998; 148(1): 45-50.

10 Mendelsohn AB, Belle SH, Stoehr GP, Ganguli M. Use of antioxidant supplements and its association with cognitive function in a rural elderly cohort: the MoVIES Project. Am.J. Epidemiol. 1998; 148(1): 38-44.

11 Sano M, Ernesto C, Thomas RG, et al. A controlled trial of selegiline, alpha-tocopherol, or both as treatment for Alzheimer's disease. N. Engl. J. Med. 1997; 336: 1216-22.

12 Srám RJ, Binková B, Topinka J, et al. Effect of antioxidant supplementation in an elderly population. In: Bronzetti G. et al., eds. Antimutagenesis and Anticarcinogenesis Mechanisms, Vol. III. New York: Plenum Press, 1993; 459-77.
13 Cerhan JR, Folsom AR, Mortimer JA, et al. Correlates of cognitive function in middle-aged adults. Gerontology 1998; 44: 95-105.

14 ARIC Investigators. The Atherosclerosis Risk in Communities (ARIC) study: design and objectives. Am. J. Epidemiol. 1989; 129: 687-702.

15 Knopman DS, Ryberg S. A verbal memory test with high predictive accuracy for dementia of the Alzheimer type. Arch. Neurol. 1989; 46: 141-5.

16 Wechsler D. WAIS-R Manual. Cleveland: The Psychologic Corporation, 1981.

17 Lezak MD. Neurological Assessment, 2nd edn. New York: Oxford University Press, 1983.

18 Benton AL, Hamsher K. Multilingual Aphasia Examination, 2nd edn. Iowa City: AJA Associates, 1989.

19 Wechsler D. The Measurement and Appraisal of Adult Intelligence. Baltimore: Williams and Williams, 1958.

20 Russell EW. A WAIS factor analysis with brain damaged subjects using criterion measures. J. Consult. Clin. Psychol. 1972; 39: 133-9.

21 Tranel D. Neuropsychological assessment. Psychiatr. Clin. North Am. 1992; 15: 283-99.

22 Franzen MD. Multilingual aphasia examination. In: Keyser DJ, Sweetland RC, eds. Test Critiques, Vol. 5. Kansas City: Test Corporation of America, 1986; 278-82.

23 Willett WC, Sampson L, Stampfer MJ, et al. Reproducibility and validity of a semiquantitative food frequency questionnaire. Am. J. Epidemiol. 1985; 122: 51-65.

24 Stevens J, Metcalf PA, Dennis BH, Tell GS, Shimakawa T, Folsom AR. Reliability of a food frequency questionnaire by ethnicity, gender, age, and education. Nutr. Res. 1996; 16(5): $735-45$.

25 Bond MG, Barnes RW, Riley WA, et al. High resolution Bmode ultrasound scanning methods in the Atherosclerosis Risk in Communities Study (ARIC) cohort. J. Neuroimag. 1991; 1: 68-73.

26 Riley WA, Barnes RW, Bond MG, Evans GW, Chambless LE, Heiss G, for the ARIC Study Group. High resolution Bmode ultrasound reading methods in the Atherosclerosis Risk in Communities (ARIC) cohort. J. Neuroimag. 1991; 1: $168-72$

27 Dempster AP, Laird NM, Rubin DB. Maximum likelihood from incomplete data via the EM algorithm (with discussion). J. Roy. Stat. Soc. 1977; B39: 1-38.

28 Clauss A. Gerinnungsphysiologische Schnellmethode zur Bestimmung des Fibrinogens. Acta Haematol. 1957; 17: 237-46.

29 Appels A, Höppener P, Mulder P. A questionnaire to assess premonitory symptoms of myocardial infarction. Int. J. Cardiol. 1987; 17: 15-24.

30 Schneider LS. New therapeutic approaches to Alzheimer's disease. J. Clin. Psychiatry 1996; 57(Suppl. 14): 30-6.

31 Parnetti L, Senin U, Mecocci P. Cognitive enhancement therapy for Alzheimer's disease: the way forward. Drugs 1997; 53(5): 752-68.

32 Benton D, Fordy J, Haller J. The impact of long-term vitamin supplementation on cognitive functioning. Psychopharmacology 1995; 117: 298-305. 